\title{
TREATMENT OF UNCERTAINTIES IN THE EXISTENCE OF FREE BERTHS WITH RISK ANALYSIS TECHNIQUES. ESTABLISHMENT OF POLICIES IN PORT OF CADIZ (SPAIN)
}

\author{
Samir Awad Núñez \\ Researcher, Universidad Politécnica de Madrid, Spain \\ Alberto Camarero Orive \\ University Lecturer, Universidad Politécnica de Madrid, Spain \\ María Romero Sánchez-Brunete \\ MSc Student, Universidad Politécnica de Madrid, Spain \\ Alfonso Camarero Orive \\ Researcher, Universidad Politécnica de Madrid, Spain \\ Nicoletta González Cancelas \\ University Assistant Lecturer, Universidad Politécnica de Madrid, Spain
}

\begin{abstract}
This research discusses the challenges involved in the treatment of uncertainties in the existence of free berths during the arrival of cruise ships at seaports. Pursuing this goal, a three-step methodology is adopted: 1) Identifying risk sources and critical risk variables and how they are related; 2) Fitting the Probability Distribution Functions that best represent the behaviour of each critical risk variable; and 3) Simulating the probability of a ship having to wait because there are no free berths using a technique that combines statistical concepts (random sampling) with the ability of computers to generate pseudorandom numbers and automate estimations of the values of the set of critical risk variables. The innovative use of risk analysis techniques in this field allows the establishment of policies to improve the planning and management of port infrastructure, for example, deciding when it is necessary to work to increase the number of berths. As a case of study, we applied this methodology to study whether the enlargement of the wharf in the port of Cadiz (Spain) is necessary right now considering the number of cruise ships that have arrived at the port in the past three years, their date and hour of arrival, their length and draught, the duration of their stay in port and their waiting time before being able to enter the port. This action would require moving logistics activities to a new terminal, but would bring to the city the opportunity to rethink the seafront, introducing new cruiser links with the city centre and developing a better seaport-city integration.
\end{abstract}

\section{INTRODUCTION}

In recent years, the development, implementation, and application of risk assessment methods have become increasingly common in the maritime scope for such issues as: using system simulation to model the impact of human error in a maritime system (Harrald et al., 1998), safety of oil transportation (Merrick et al., 2000), risk modelling in distributed large-scale systems (Grabowski et al., 2001), and a risk assessment approach to improve 
the resilience of a seaport system using Bayesian networks (John et al., 2016). These are just a few references that reflect the importance of this method, which is commonly used to mitigate and control hazards.

Risk assessment is the way in which companies understand how significant each risk is to the achievement of their overall goals. To accomplish this, companies require a risk assessment process that is practical, sustainable, and easy to understand. The process must proceed in a structured and disciplined fashion (Curtis and Carey, 2012). Risk analyses cannot remove all risk; however, they can assist in managing and reducing risks. There is a widespread perception that risk analysis provides useful support for decision-makers in designing proper measures to respond to potential events (Aven, 2010; Aven, 2015). It allows organisations to plan, prioritise, and perform work taking a deliberately risk-aware approach (Renn, 2008).

However, it is also possible to use this method for other applications in the maritime scope. Risk analysis makes sense when non-recurring events are being studied. With this in mind, a risk analysis technique has been adopted in this research; in this particular case the phenomenon being investigated is the probability that a cruise ship has to wait for berthing in a wharf, because unlike some other types of ship, not all cruises sail regular routes, so some companies do not need to rent berths for their cruises. This means that cruise liners often have to share the use of berths with other liners, or even other types of vessel, and in consequence to queue for available berths at a busy port, which reduces efficiency for the operating companies, and creates undesirable drawbacks for cruise passengers who access the port area with logistical and industrial activities. This paper evaluates this fact and facilitates decision-making with the goal of Cadiz coordinating solutions for the problems arising from the port-city relationship in order to obtain a sustainable urban solution that contributes to the harmonious coexistence of the port and the city, in terms of urban design and respect for the environment. The technique applied combines statistical concepts with the generation of pseudo-random numbers and the automation of estimates on the critical risk values for different sets of variables on the existence of free berths.

The present paper is organized as follows. Section 2 provides a brief overview of the evolution of risk assessment in port issues as well as different methods of study to deal with uncertainty in the existence of free berths during the arrival of vessels such as cruise liners, containers, bulk carriers, etc. As with any project risk management process, it must be tailored to the particular circumstances of the project and of the organization undertaking it. Section 3 explains the methodology adopted, using risk management techniques, in order to interpret the risk when transport demand is close to exceeding the capacity of the port facilities. After that, factors influencing possible simplifications of the generic process are identified, and simplifications are proposed for some cases. Then the application to a real project is presented in Section 4 and its results are summarized in Section 5. Finally, Section 6 closes with some conclusions that can be used to establish policies and therefore to improve the planning and management of port infrastructure. The implications of these considerations refer to the case of study of the Port of Cadiz but the methodology and the improvements that it provides over other techniques can be applied in new areas. 


\section{A BRIEF OVERVIEW OF PORT CONGESTION, QUEUING THEORY AND RISK MANAGEMENT}

Maduka (2004) and Onwumere (2008) refer to port congestion as a situation where, in a port, arriving ships have to wait in a queue before berthing, or spend more time at berth than usual before being worked on because of inadequate port facilities. Adedayo et al. (2006) define it as situations which require a ship to queue before being attended to and it occurs when the capacity of service is close to the demand. Warwar (1980) defines berth occupancy as the ratio of berth waiting time to berth serving time. According to Fararoui (1989), the number of available berths is an obvious factor in determining whether queues of ships will be formed and what their length will be. Zrnic et al. (1999) expound that the time between the arrival of ships and their departure is the main factor that determinates the capacity of ports. Other researchers prefer another approach and focus on the study of port efficiency as in the case of Wanke (2013) and Serebrisky et al. (2016). But this latter approach is difficult to replicate to analyze the dataset available for this work. Future research with new recorded data may study the port efficiency.

Secondly, queuing theory is a way to think about port congestion problems since it provides port managers with a useful set of decision-making formulas and algorithms for designing port facilities and services (Kalavaty, 2007). Some researchers have applied this theory to analyze port congestion. Sen (1980) addresses the issue of introducing priorities for the analysis of congestion problems to minimize the average cost of waiting in a queuing system. Kozan (1994) applies queuing simulation models to determine an optimal balance between the opportunity cost of ship waiting time and the cost incurred in the expansion of the seaport system. Dragović et al. (2006) discuss simulation and queuing models in order to determine the performance evaluation of the ship-berth link in port.

Kiani et al. (2006) address both berth unproductive time and container ships' turnaround times. This helps the port operator to minimize the turnaround time either by expanding the capacity of their berths or by increasing their service rate. Also studying the traffic of containers, Laih et al. (2007) design a toll scheme for queuing container ships at a busy port, in which container ships' arrival times at the busy port will be rationally dispersed and, consequently, all container ships' queuing times can be decreased. Moreover, Laih and Chen (2008) derive a series of the n-step toll scheme for container ships at a busy port with only one berth and the consequent changes of container ships' arrival schedules. In order to extend the previous research, Laih and Sun (2013) consider a different situation of multiple berths available at a busy port, which makes its model of queuing pricing more applicable to port authorities.

Of considerable interest for this research is the work of Sanish (2007). That paper observes that queuing theory can be used to predict important parameters like average waiting time of ships, average queue length, average number of ships and average berth utilization factor.

Queuing theory can also be used to analyze decisions to invest in new berth construction to reduce waiting time. Naima et al. (2016) apply it in order to analyze congestion at the Manila International Container Terminal in the Port of Manila, where vessels had to wait in a queue because of congestion. The results revealed that the number of berths was adequate, so port managers should take other actions to release congestion. In the same 
way, we have applied queuing theory to evaluate whether the enlargement of the cruise wharf in the port of Cadiz is necessary right now.

On the other hand, while there is a relatively large literature about queuing theory, much less attention has been paid to the effects of demand uncertainty on costs in ports. An exception is the paper by Rodríguez-Álvarez et al. (2011), who analyzed the effect of demand uncertainty on port terminal costs in a Spanish port, finding that demand uncertainty has a significant effect on costs and can lead to over estimation of cost inefficiency for terminals which face greater demand uncertainty. Tovar and Wall (2014) contribute to this literature by investigating whether the effects of demand variability on port costs found for the port of Las Palmas hold for Spanish ports as a whole. After detecting this lack of literature on the influence of uncertain demand, we have decided to follow this path to address our study, in particular, by using risk management techniques. It is the process whereby decisions are made to accept a known or assessed risk or the implementation of action to reduce the consequences or the probability of occurrence of an adverse event (Cheng T. et al., 2012) and it refers to strategies, methods and supporting tools to identify and control risk to an acceptable level (Alhawari S. et al., 2012). This is the tool on which we base the evaluations of queues by simulating the arrival of cruise ships at seaports in order to assess the level of wharf congestion.

\section{METHODOLOGY}

This paper presents a generic project risk management process that has been modified for the treatment of uncertainties in the existence of free berths. This section describes the methodology and explains the main steps carried out in this research. These steps are shown in Figure 1.

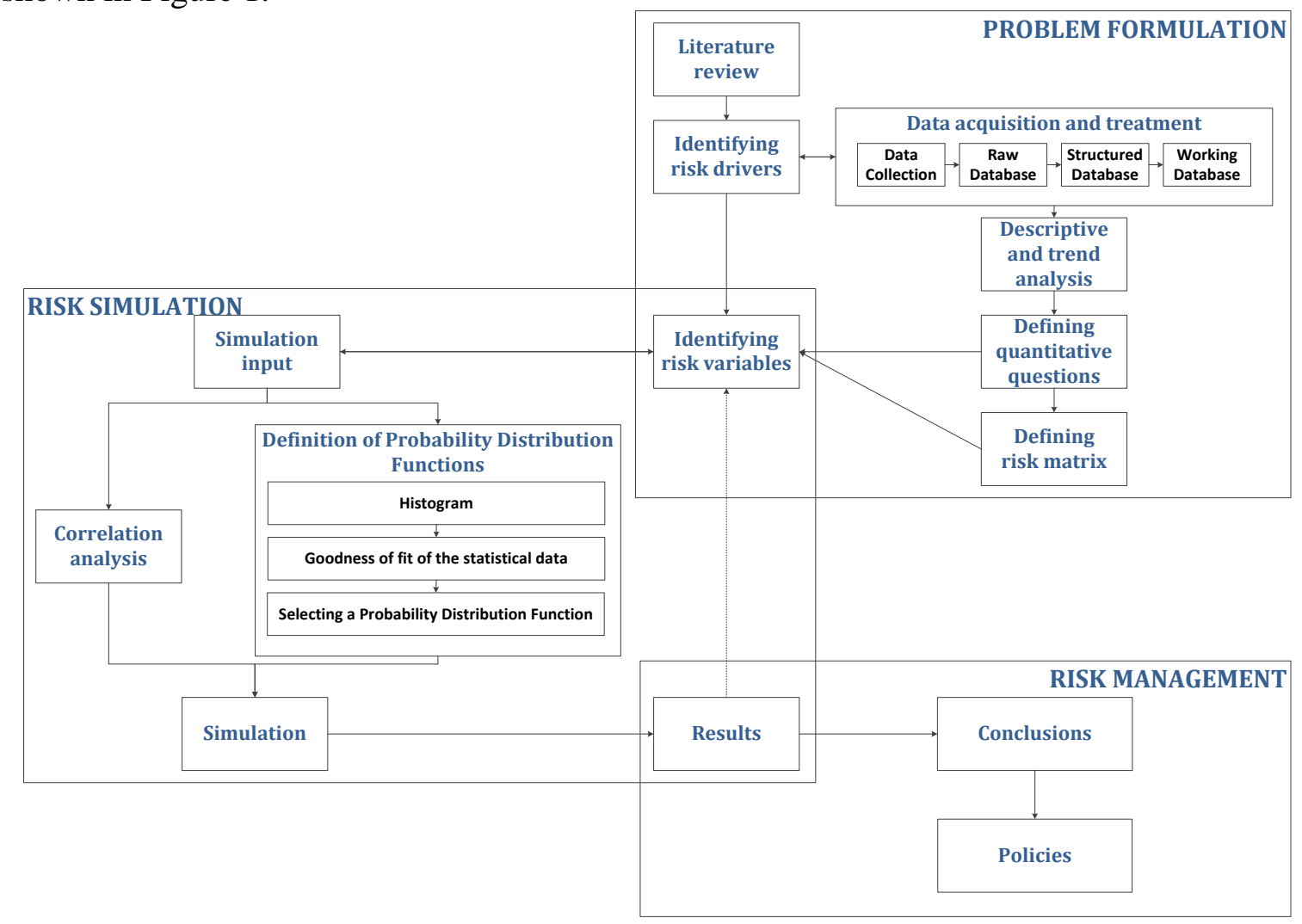

Fig. 1 - Methodology diagram 
The first step consisted of the formulation of the problem. It included a review of the main studies in the literature that are relevant to this research. We identified the main risk drivers and collected and treated the database. The data used in this research was collected from the Port Authority of the Bay of Cadiz, including all the arriving information of cruise ships and their conditions from $1^{\text {st }}$ January 2012 to $31^{\text {st }}$ December 2014. The data underwent several transformations, as shown in Figure 1, to produce a list of the cruise ship stays in port. From this list, we built a chronogram that allowed us to check the temporal overlaps in port. With this information, we built the working database. Finally, we analyzed both the qualitative and the quantitative data to identify the risk variables: 1) number of cruise ships arriving at seaports; 2) lengths of the cruise ships; 3) draughts of the cruise ships; 4) their date and hour of arrival, in order to establish their time staying in port. With these variables we can analyze the occupancy percentage of the wharf frontage or, where relevant, the waiting time before a cruise ship is able to enter the port. All this data is gathered in a table with the structure presented in Table 1.

Table 1 - Risk drivers and objectives functions

\begin{tabular}{|c|c|c|c|c|c|c|c|}
\hline \multirow{2}{*}{ Variable } & $\begin{array}{c}\text { Date and } \\
\text { time of } \\
\text { arrival }\end{array}$ & $\begin{array}{c}\text { Date and } \\
\text { time of } \\
\text { departure }\end{array}$ & $\begin{array}{c}\text { Number } \\
\text { of ships }\end{array}$ & $\begin{array}{c}\text { Ship } \\
\text { Length* }\end{array}$ & $\begin{array}{c}\text { Berth } \\
\text { Length }\end{array}$ & $\begin{array}{c}\text { Occupancy percentage } \\
\text { of the wharf frontage }\end{array}$ & Delay \\
\hline \multirow{2}{*}{$\begin{array}{c}\text { Code } \\
\text { Value }\end{array}$} & DTA & DTD & NS & SL & BL** & OPB & D \\
\cline { 2 - 8 } & $D T A_{1}$ & $D T D_{1}$ & $N S_{1}$ & $S L_{1}$ & $B L_{n}$ & $O P B_{1 n}=\left(\frac{S L_{1}}{B L_{n}}\right) * 100$ & $D_{1 n}$ \\
\cline { 2 - 8 } & $\vdots$ & $D T D_{2}$ & $N S_{2}$ & $S L_{2}$ & $B L_{n}$ & $O P B_{2 n}=\left(\frac{S L_{2}}{B L_{n}}\right) * 100$ & $D_{2 n}$ \\
\hline & $\vdots$ & $\vdots$ & $\vdots$ & $\vdots$ & $\vdots$ & $\vdots$ \\
\hline
\end{tabular}

* when there is an overlap of several cruise ships in the port, their lengths are added.

** $n$ corresponds respectively to the different berths: Alfonso XIII, Muelle Ciudad, Reina Sofía and Marqués de Comillas.

The second step included all the tasks related to the risk simulation. First, correlation analysis, which refers to any of a broad class of statistical relationships involving dependence between risk drivers, must be included in the simulation in order to avoid bias effects due to this dependence. Second, the Probability Distribution Functions that best define the behaviour of each of the analyzed risk drivers are defined. Using these Probability Distribution Functions, it is possible to simulate the behaviour of the objective function when the risk drivers $\left(N S_{m}, S L_{m}\right)$ increase by $10 \%$ and $20 \%$ (not only separately, but also jointly).

Although there are other techniques, we used the Monte Carlo Simulation Method. The main advantage of this method is that can be computerized. Thus, many iterations can be quickly obtained. In this research, 500 cases were calculated. With the results of these 500 simulations we performed a descriptive analysis that establishes the probability of occurrence of the objective variable by representing and studying risk profiles. The results of the simulation let us derive conclusions that can be used to establish policies of how to manage the reception and positioning of cruise ships but also when best to start studying the enlargement of the wharf to provide it with a greater length of cruise ship berths or, where appropriate, when best to expand the port. 


\section{CASE OF STUDY: THE PORT OF CADIZ}

As a case of study, this methodology has been applied to understand the statistical behaviour of the occupancy percentage of the wharf frontage in the port of Cadiz and, as a result, to establish measures for managing the reception and positioning of cruise ships as well as when best to start studying the enlargement of the wharf to provide it with a greater length of cruise ship berths or, where appropriate, when best to expand the port.

The Bay of Cadiz Port is located on the western seaboard of Andalucía, facing the Atlantic and close to the strait of Gibraltar, with a privileged geographical situation between the Atlantic and the North of Africa, thanks to which it has become a regular port of call for cruise vessels en route between the Mediterranean and the Caribbean. But it is not only for its geographical situation that Cadiz is chosen for these ships: the city itself, the surrounding countryside and the proximity to other tourist centres in Andalucía have stimulated interest for several operators that have included Cadiz as a regular stopping point for their Mediterranean cruises.

Currently, the usual berthing area for cruises ships, mainly Ciudad and Alfonso XIII wharfs, is integrated in the urban centre of the city. The distance from the passenger terminal to the city centre is barely 5 minutes' walk, while industrial activities have been moved away from it.

The most important technical characteristics of Cadiz - City Basin and the main technical characteristics of wharfs destined partially or exclusively to cruises are gathered in Figure 2.

\begin{tabular}{|c|c|c|c|c|c|c|}
\hline Location & & \multicolumn{4}{|c|}{ Longitude: $6^{\circ} 17^{\prime}$ West; Latitude: $36^{\circ} 32^{\prime}$ North } & \\
\hline Entrance $\mathrm{Ch}$ & nnel & \multicolumn{5}{|c|}{ Width: $250 \mathrm{~m}$; Longitude: $3.600 \mathrm{~m}$; Depth at low tide: $13 \mathrm{~m}$} \\
\hline Sheltered water & surface & \multicolumn{5}{|c|}{224 hectares } \\
\hline Land surfa & & \multicolumn{5}{|l|}{70 hectares } \\
\hline Use & & \multicolumn{5}{|c|}{ Commercial, Fishing, Cruises and Sailing } \\
\hline \multicolumn{7}{|c|}{ MARQUÉS DE COMILLAS RE RINA SOFÍA } \\
\hline & \multicolumn{2}{|c|}{ Wharf } & Draught & Length & Traffic & Equipment \\
\hline & \multicolumn{2}{|c|}{ Alfonso XIII } & $10 \mathrm{~m}$ & $324 \mathrm{~m}$ & Cruises & Cruise Terminal \\
\hline & \multicolumn{2}{|c|}{ Ciudad } & $10 \mathrm{~m}$ & $316 \mathrm{~m}$ & Cruises & Cruise Terminal \\
\hline & \multicolumn{2}{|c|}{ Reina Sofia } & $10,5 \mathrm{~m}$ & $600 \mathrm{~m}$ & Cruises and Containers & 3 container cranes 40 \\
\hline & \multicolumn{2}{|c|}{ Marqués de Comillas } & $10 \mathrm{~m}$ & $950 \mathrm{~m}$ & General, Cruises and Ro-Ro & Warehouse and storage pit \\
\hline
\end{tabular}

Fig. 2 - Map of the Port of Cadiz (Cadiz Bay Port Authority)

\section{RESULTS AND DISCUSSION}

This section summarizes the main findings from the analysis conducted in this research.

Following the methodology presented above, we built a chronogram of all the cruise stay times in port. In case of overlap, the length of the cruises are added and the $O P B_{m n}$ of each berth and of the total length of wharf in the whole port can be calculated. 
The developed simulations are taken from the observed case (the list of arrivals between 2012 and 2014) to $+20 \% N S_{m}$ and $+20 \% S L_{m}$ cases. Due to the random nature of the arrival of cruise ships which follow a Poisson distribution (as expected, since the arrival of a cruise involves the occurrence of an event with very small probabilities observed over a long period) and the composition of the fleet that reaches the Port of Cadiz, no correlation was observed between the risk drivers. Thus, the simulation frees the variation and combination of the risk variables.

Each simulation gives a result of the objective variables. No value is obtained for the variable $D_{m n}$ in any case. So, only $O P B_{m n}$ risk profiles are drawn. Figure 3 summarizes the Probability Distribution Functions of the $O P B_{m n}$ of each wharf and their respective risk profiles, representing in the abscissa axis the number of cases assessed and in the ordinate axis the occupancy percentage of the wharf frontage.

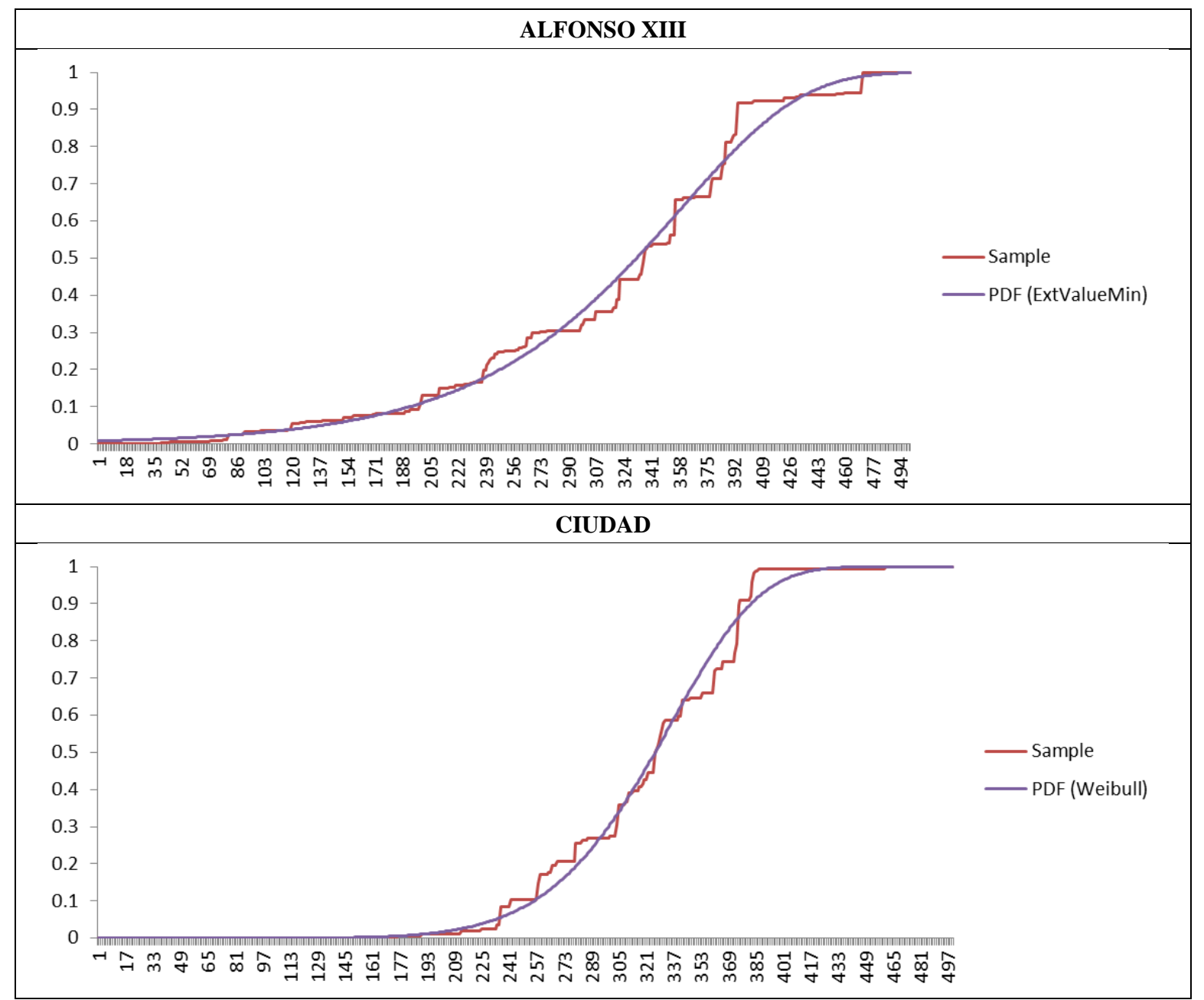

Fig. 3 - Fitted Probability Distribution Functions Risk Profiles for each wharf 


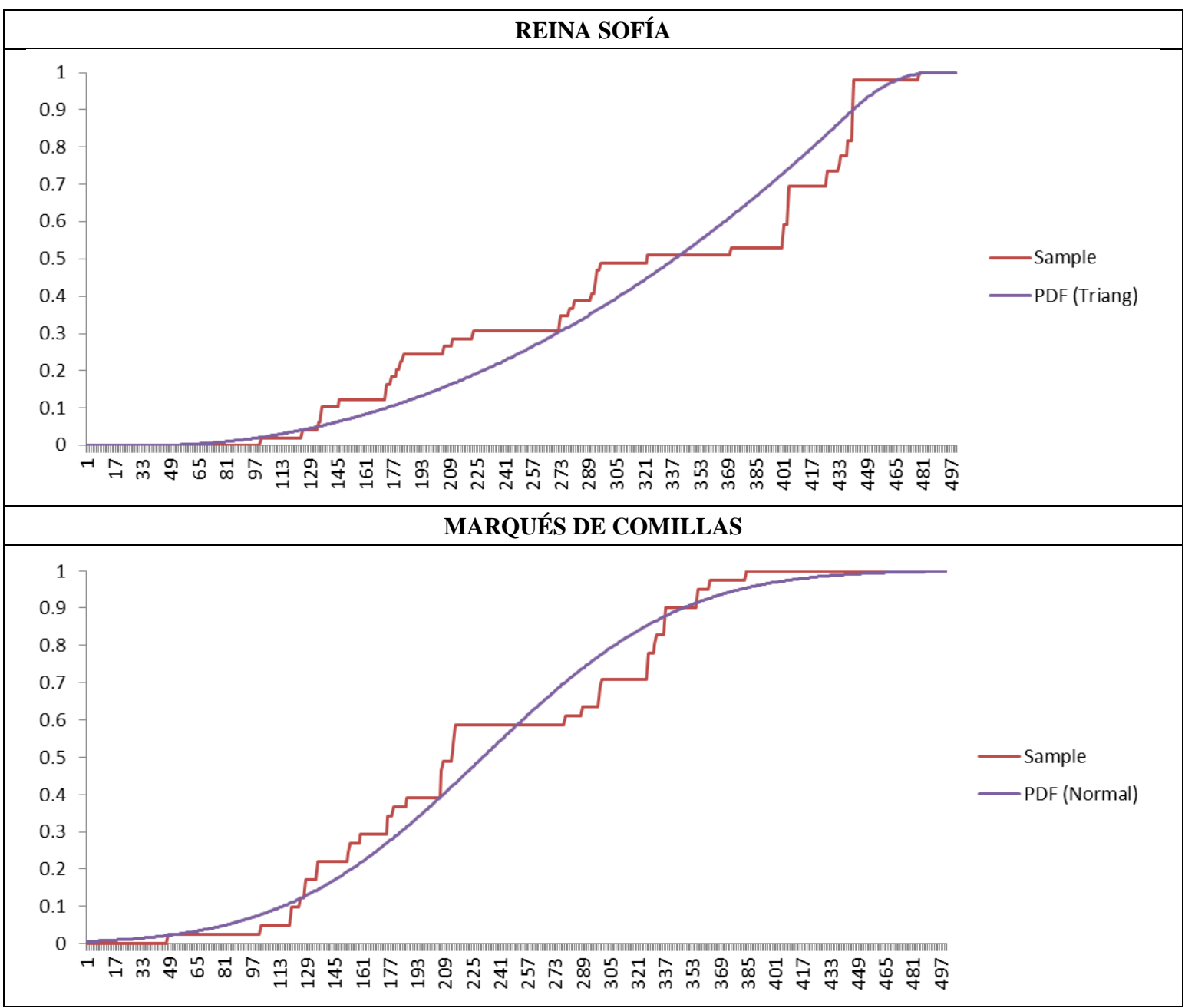

Fig. 3 - Fitted Probability Distribution Functions Risk Profiles for each wharf (continued)

Thus, the set of simulations indicate that the Alfonso XIII wharf has occupancy higher than $80 \%$ in 104 cases and is full in 6 cases of the total of 500 cases. Ciudad has this occupancy in 136 cases and is full in 83 cases, due to its small length (often it is full with only one cruise ship). Reina Sofía is occupied more than $80 \%$ in 84 cases and is full in 19 cases. Finally, Marqués de Comillas has this occupancy in 187 cases and is full in 39 cases. However, even if the occupations may seem to cause delays in cruise ship arrivals, this doesn’t occur, as shown in Figure 4.

It is demonstrated that, for traffic from 2012 to 2014, when taking into account all passenger wharfs of the port, the occupancy percentage is very low. The most likely occupations are between $10 \%$ and $25 \%$ and occupancies of over $40 \%$ can be considered as outlier events.

Applying the same criteria used in simulation of wharf-by-wharf analysis (up to $+20 \%$ $N S_{m}$ and $+20 \% S L_{m}$ cases, as well as combinations of both), the risk profile of the global analysis indicates that occupancy higher than $80 \%$ is only reached in 51 cases and only 10 simulations fill all the wharfs. 


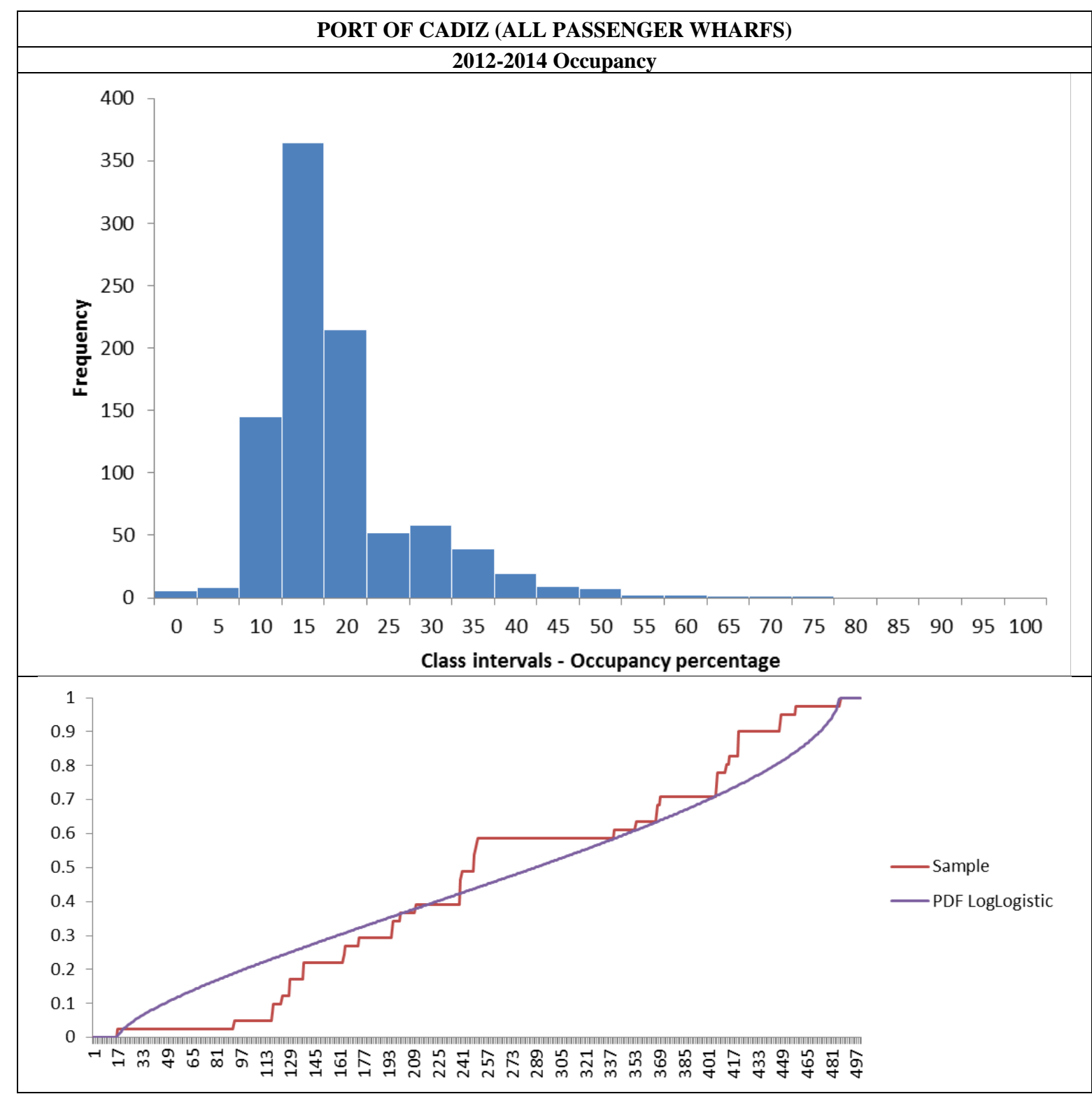

Fig. 4 - Fitted Probability Distribution Function Risk Profile taking into account all the wharf length

\section{CONCLUSIONS AND POLICIES}

This research shows how to deal with risk analysis for the study of the simulation of nonrecurring events. In particular, the case of arrival times of cruise ships to the port of Cadiz is studied. This methodology operates efficiently and one of its main advantages is that the cumulative graphs obtained are very easy to interpret not only by scientists, but also by decision makers. So they can help to interpret occupation problems of berths and to set thresholds to determine when it is appropriate to extend a wharf or, where appropriate, to expand the port and reorganize its activities.

In the case we studied, the Port of Cadiz has a new container terminal that was completed a few years ago and may be brought into operation in the next few months. The transportation capacity at the new terminal will allow reorganization of the activities at the 
Reina Sofia and Marqués de Comillas wharfs. As the results of the risk analysis indicate, the berths Alfonso XIII and Ciudad would be congested with increases up to $+20 \% N S_{m}$ and $+20 \% S L_{m}$, since $80 \%$ occupancy is exceeded in more than 100 cases in the 500 evaluated simulations. Thus, the results show the need to dedicate exclusively to passengers one or both of the wharfs that are currently serving both cruise ships and freight traffic.

The results also show that if the two wharfs became specialized, the port capacity for the arrival of cruise ships would be excessive. In the light of the results of this assessment, the specialization of only one of the berths is recommended. In deciding which one should be dedicated to passengers, other elements which require the knowledge of the port, the city and the relationship between the two come into play. In the case of Cadiz, the port needs direct connections that can't be built behind the Reina Sofia wharf. In addition, this part of town has significant social degradation problems caused by the impact of logistics and industrial activities that could be resolved by recovering part of the port area for the use of citizens and visitors. It also seems advisable that the restructuring of the activities of the port involves the specialization of the Reina Sofía wharf. This reorganization requires transferring its logistics to the new container terminal activities and an appropriate urban and transport plan to make the new structure of the activities compatible with the environment. With these policies, the recent construction of the new terminal with the objective to allow the Port of Cadiz to de-congest the freight traffic will also be an opportunity to improve the port-city integration.

For its part, the Marqués de Comillas wharf can continue serving both passengers and freight. If the cruise ship arrivals during the next few years continue to be registered it will be possible to establish when it becomes necessary for this wharf to also become specialized. In addition, the scope of this research excludes time trends (due to the availability of data); it would be interesting for future research to deepen (with more data available) in this area by incorporating the time variation of cruise ship arrivals in port.

\section{REFERENCES}

Adedayo O. A., Ojo O., and Obamiro J. K. (2006). Operations Research in Decision Analysis and Production.

Alhawari, S., Karadsheh, L., Talet, A. N., and Mansour, E. (2012). Knowledge-based risk management framework for information technology project. International Journal of Information Management, 32(1), 50-65.

Aven, T. (2010). Some reflections on uncertainty analysis and management. Reliability Engineering \& System Safety, 95(3), 195-201.

Aven, T. (2015). Implications of black swans to the foundations and practice of risk assessment and management. Reliability Engineering \& System Safety,134, 83-91.

Cheng, T. C. E., Yip, F. K., and Yeung, A. C. L. (2012). Supply risk management via guanxi in the Chinese business context: the buyer's perspective.International Journal of Production Economics, 139(1), 3-13. 
Curtis, P. and Carey, M. (2012). Risk Assessment in Practice. Working Paper, Deloitte \& Touche LLP, Research Commissioned by COSO (Committee of Sponsoring Organizations of the Treadway Commission).

Dragović, B., Park, N. K., and Radmilović, Z. (2006). Ship-berth link performance evaluation: simulation and analytical approaches. Maritime Policy \& Management, 33(3), 281-299.

Fararoui, F. (1989). Queuing theory and berthing optimization, PhD thesis dissertation, Pumark Educational Publishers, Lagos, Nigeria.

Grabowski, M., Merrick J., Harrald J., Mazzuchi T., and Van Dorp J. R. (2001). Risk Modeling in Distributed, Large-Scale Systems, IEEE Systems, Man \& Cybernetics Part A: Systems and Humans.

Harrald, J. R., Mazzuchi, T. A., Spahn, J., Van Dorp, R., Merrick, J., Shrestha, S., and Grabowski, M. (1998). Using system simulation to model the impact of human error in a maritime system. Safety Science, 30(1), 235-247.

John, A., Yang, Z., Riahi, R., and Wang, J. (2016). A risk assessment approach to improve the resilience of a seaport system using Bayesian networks. Ocean Engineering, 111, 136-147.

Kalavaty, S. (2007) Operations research. Second edition. Vikas Publishing house PVT Ltd., New Delhi, India.

Kiani, M., Bonsall, S., Wang, J., and Wall, A. (2006). A break-even model for evaluating the cost of container ships waiting times and berth unproductive times in automated quayside operations. WMU Journal of Maritime Affairs, 5(2), 153-179.

Kozan, E. (1994). Analysis of the economic effects of alternative investment decisions for seaport systems. Transportation planning and Technology, 18(3), 239-248.

Laih, C. H., \& Sun, P. Y. (2013). Effects of the optimal n-step toll scheme on bulk carriers queuing for multiple berths at a busy port. Transport Policy, 28, 42-50.

Laih, C. H., and Chen, K. Y. (2008). Economics on the optimal n-step toll scheme for a queuing port. Applied Economics, 40(2), 209-228.

Laih, C. H., Lin, B., and Chen, K. Y. (2007). Effects of the optimal port queuing pricing on arrival decisions for container ships. Applied Economics, 39(14), 1855-1865.

Maduka (2004). Port, Shipping, Safety and Environmental Management. Concept Publication Ltd., Lagos, Nigeria.

Merrick, J. R., van Dorp, J. R., Harrald, J., Mazzuchi, T., Spahn, J. E., and Grabowski, M. (2000). A systems approach to managing oil transportation risk in Prince William Sound. Systems Engineering, 3(3), 128-142. 
Onwumere, (2008). Handout on Maritime Transport, Operations and Management, Certified Institute of Shipping, Lagos, Nigeria.

Renn, O. (2008). Risk governance: coping with uncertainty in a complex world. Earthscan. Rodríguez-Álvarez, A., Tovar, B., \& Wall, A. (2011). The effect of demand uncertainty on port terminal costs. Journal of Transport Economics and Policy (JTEP), 45(2), 303328.

Saeed, N., \& Larsen, O. I. (2016). Application of queuing methodology to analyze congestion: A case study of the Manila International Container Terminal, Philippines. Case Studies on Transport Policy.

Sanish A. (2007). Application of queuing model and simulation to the traffic at new Mangalore port, Working paper, Department of Applied Mechanics and Hydraulics, NITK Surathkal. Karnataka, India.

Sen, P. (1980). Optimal priority assignment in queues: application to marine congestion problems. Maritime Policy and Management, 7(3), 175-184.

Serebrisky, T., Sarriera, J. M., Suárez-Alemán, A., Araya, G., Briceño-Garmendía, C., \& Schwartz, J. (2016). Exploring the drivers of port efficiency in Latin America and the Caribbean. Transport Policy, 45, 31-45.

Tovar, B., and Wall, A. (2014). The impact of demand uncertainty on port infrastructure costs: Useful information for regulators?. Transport Policy, 33, 176-183.

Wanke, P. F. (2013). Physical infrastructure and shipment consolidation efficiency drivers in Brazilian ports: A two-stage network-DEA approach.Transport Policy, 29, 145153.

Warwar, J. F. (1980). Port capacity methodology--simplified. Publication of: American Society of Civil Engineers.

Zrnic, D. N., Dragović, B. M., \& Radmilovic, Z. R. (1999). Anchorage-ship-berth link as multiple server queuing system. Journal of waterway, port, coastal, and ocean engineering, 125(5), 232-240. 